Engineering, Technology and Techniques

Vol.59: e16161053, January-December 2016 http://dx.doi.org/10.1590/1678-4324-2016161053 ISSN 1678-4324 Online Edition

\title{
Nano Coated Lead Free Solders for Sustainable Electronic Waste Management
}

\author{
K.Arun Vasantha Geethan ${ }^{1}$, S.Jose ${ }^{2}$, S.Ashwin Kannan ${ }^{1}$, J.Immanuel Durai Raj $^{1}$, Ramesh \\ k. ${ }^{2}$. \\ ${ }^{I}$ Department of Mechanical Engineering, St Joseph's Institute of Technology, Chennai, India. ${ }^{2}$ Department of \\ Mechanical Engineering, Loyola- ICAM College of Engineering \& Technology, Chennai, India.
}

\begin{abstract}
Lead has been used in a wide range of applications, but in the past decades it became clear that its high toxicity could cause various problems. Studies indicate that exposure to high concentrations of lead can cause harmful damages to humans. To eliminate the usage of lead in electronic products as an initiative towards electronic waste management (e waste), lead free solders were produced with suitable methods by replacing lead. But lead free solders are not preferred as a substitute of lead because they are poor in their mechanical properties such as tensile strength, shear strength and hardness which are ultimately required for a material to resist failure.Nano-Structured materials and coatings offer the potential for Vital improvements in engineering properties based on improvements in physical and mechanical properties resulting from reducing micro structural features by factors of 100 to 1000 times compared to current engineering materials.
\end{abstract}

Key words: E-waste, nano-structured materials, lead free, management

\footnotetext{
*Author for correspondence: kavgeeth@gmail.com
} 


\section{INTRODUCTION}

Soldering process involves the use of solders which has lead in its composition at $37 \%$. From a industry, company or a service provider point of view, lead free solders are not preferred since they receive lots of complaints from customers due to the less working life of soldered material and that hinders the company reputation. Thus to increase the usage of Lead free solders, the above defects is reduced by increasing the mechanical strength of the Solder. This is done by Nano Structured Coatings. The potential benefits which include higher hardness and strength in metals can be achieved by reducing grain size and slip distance, respectively. [1]Composite lead-free solders, containing micro and nano particles, have been experimented and found that due to grain boundary drag or Zener drag, these particles can refrain the solder microstructure from coarsening in services, especially for Cu6Sn5, Ag3Sn intermetallic compounds and the b-Sn phases.[2]The resistor chip (RC) micro joints were soldered using nano$\mathrm{Al}_{2} \mathrm{O}_{3}$ particlereinforced $\mathrm{Sn}-\mathrm{Ag}-\mathrm{Cu}$ solder paste. The microstructure and reliability of $\mathrm{RC}$ micro joints having different nano $\mathrm{Al}_{2} \mathrm{O}_{3}$ contents $(0,0.25,0.5$ and 1.0 wt $\%)$ were investigated in detail. [3] This study investigates the effects of the addition of $\mathrm{Fe}_{2} \mathrm{NiO}_{4}$ nanoparticles into a SAC-305 lead-free solder paste. Iron, nickel, and oxide nanoelements were mixed with $\mathrm{Pb}$-free solder alloying elements to produce a new form of nanocomposite solder paste, which can be a promising material in electronic usage. [4]Different diamond nanoparticles amounts $(0.5,1.5$, and 2.5 wt.\%) were mechanically mixed with SAC 305 to produce a new form of nanocomposite solder paste. The characteristics of the nanocomposite solder, such as melting point, morphology and thickness of the intermetallic compound (IMC), agglomeration of diamond nanoparticles, and hardness, were investigated .[5]In this study, 0.5, 1.5, and 2.5 nominal wt.\% NiO nanoparticles were mechanically mixed with SAC 305 solder paste. The overall results indicated that $\mathrm{NiO}$ nanoparticles were dissolved with SAC 305 solder alloys during reflow soldering process.[6]In this research, Sn57.6Bi0.4Ag solder joints with different content of CNTs and Ni-CNTs were studied. The melting point of Sn57.6Bi0.4Ag solder alloy was found to be hardly influenced by small amount of these dopants. [7]The weight percentages of Ag-nanoparticle-modified grapheme (Ag-GNSs) were incorporated into $\mathrm{Pb}$-free $\mathrm{Sn}-\mathrm{Ag}-\mathrm{Cu}(\mathrm{SAC})$ solder matrices via ball milling and mechanical mixing methods to form composite solders.

\section{MATERIAL AND METHODS}

\section{SEM ANALYSIS}

A scanning electron microscope (SEM) is a type of electron microscope that images a sample by scanning it with a beam of electrons in a raster scan pattern. The electrons interact with the atoms that make up the sample producing signals that contain information about the sample's surface topography, composition, particle size and other properties such as electrical conductivity. The Figure. 1A shows the SEM analysis of zirconia particles in micro metre size. 

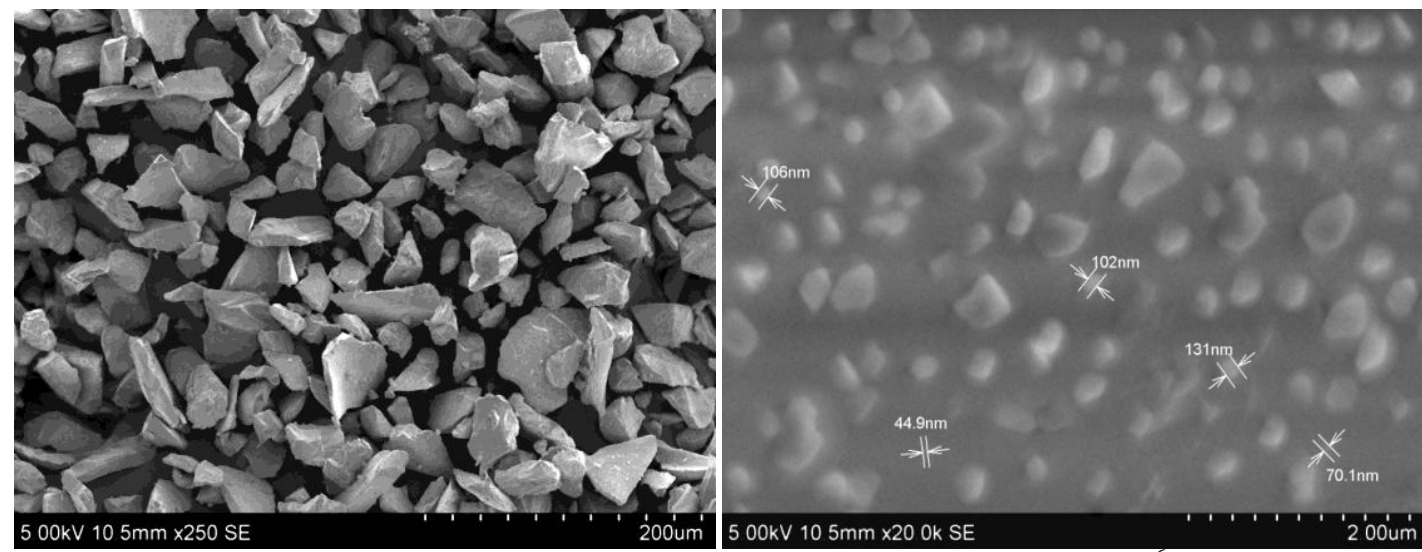

Fig. 1A, B Initial and Final SEM image showing the size of powder to be in Micro $\left(10^{-6}\right)$ metre and Nano $\left(10^{-9}\right)$ Metre

The Figure.1B confirms zirconia particles are of nano size and they are now ready to be given nano structured coating at a thickness of $2 \mu \mathrm{M}$ using physical vapour deposition technique.

\section{NANO STRUCTURED COATINGS}

Physical vapour deposition or PVD takes place in a box type coating unit which is a form of nanostructure coating technique in which a target anode is bombarded with an electron beam given off by a charged tungsten filament under high vacuum. The electron beam causes atoms from the target to transform into the gaseous phase. These atoms then precipitate into solid form, coating everything in the vacuum chamber (within line of sight) with a thin layer of the anode material. In a PVD system, the deposition chamber is evacuated to a pressure of 0.013 Pascal. The material to be evaporated is in the form of pellets. Electron beams can be generated by thermionic emission, field electron emission or the anodic arc method. The generated electron beam is accelerated to a high kinetic energy and focused towards the pellet.

\section{RESULTS AND DISCUSSION}

\section{Testing Processes \\ Test Specimen}

A tensile specimen is a standardized sample cross-section. The shoulders are large so they can be readily gripped, whereas the gauge section has a smaller crosssection so that the deformation and failure can occur in this area. The shoulders of the test specimen can be manufactured in various ways to mate to various grips in the testing machine. Threaded shoulders and grips also assure good alignment, but the technician must know to thread each shoulder into the grip at least one diameter's length, otherwise the threads can strip before the specimen fractures. Thus the $\mathrm{Sn} / \mathrm{Cu}$ lead free soldering was done on the copper specimen that was obtained by machining the copper rod as per the following tensile testing specimen requirements. The soldering is done using the lead free $\mathrm{Sn} / \mathrm{Cu}$ solder with and without the Nano-Structured Coating of Zirconium oxide Nano particles and using different gaseous flames. The soldering is done using the lead free $\mathrm{Sn} / \mathrm{Cu}$ solder with and without the Nano-Structured Coating of Zirconium oxide Nano particles and using different gaseous flames. 


\section{Ultimate Yield Strength Testing of the Lead Free Solders}

Yield strength testing involves taking a small sample with a fixed cross-section area, and then pulling it with a controlled, gradually increasing force until the sample changes shape or breaks. Longitudinal and/or transverse strain is recorded using mechanical or optical extensometers.

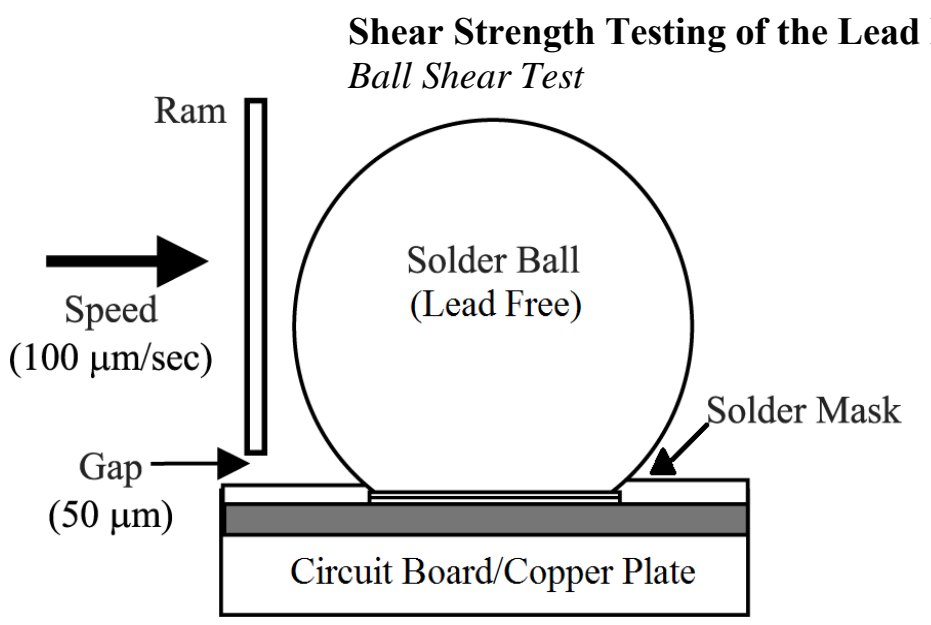

Fig.2 Schematic Representation of Ball Shear Test

Solder balls of lead free solders having a diameter ranging from $2 \mathrm{~mm}-4 \mathrm{~mm}$ were used in this study as shown in Figure.2. The substrate was a Copper plate solders bond pads/Circuit Boards. The solder balls were bonded to the substrate using Surface mounting technique with a maximum temperature of $250{ }^{\circ} \mathrm{C}$ for 60 seconds. Initially, the shearing tool is positioned beside the ball bond to be tested. The shearing arm then moves the tool horizontally against the ball, in effect pushing the ball off its bond pad. The force needed to shear a ball off its pad, known as the bond shear force, is then measured by the ball shear tester.

Shear Strength $=$ Ball Shear Force/ Ball Diameter

\section{Micro Hardness Testing Machine}

Thus the above four mechanical testing were done on different soldering parameters to check the feasibility of the Nano structured Coating application of $\mathrm{ZrO} 2$ Nano particles on Lead Free solders. The different parameters considered are Soldering done by the application of Oxygen + Acetylene flame, Soldering done by the application of Oxygen + Propane flame., Soldering done using $\mathrm{Sn} / \mathrm{Cu}$ Solder with the Nano Structured coating application., Soldering done using $\mathrm{Sn} / \mathrm{Cu}$ Solder without the Nano Structured coating application. Additionally the Nano structured coating's characteristic feature to improve the mechanical strength is also confirmed and verified by applying all the above parameters in $\mathrm{Sn} / \mathrm{Ag} / \mathrm{Cu}$ solder at a composition of $\mathrm{Sn} 96.5 / \mathrm{Ag} 3 / \mathrm{Cu} 0.5$ with a melting point of $217^{\circ} \mathrm{C}$.

\section{Test Observations}

Table. 1 depicts the results obtained after performing tensile tests, hardness test and shear test for the soldered specimens with and without the nanostructure zirconium oxide coating. 
Electronic waste management for sustainable growth

Table.1 Test observation

\begin{tabular}{|c|c|c|c|c|c|c|}
\hline $\begin{array}{l}\text { Type of lead free } \\
\text { Solder }\end{array}$ & $\begin{array}{l}\text { Gases used for } \\
\text { Soldering }\end{array}$ & Condition & $\begin{array}{l}\text { Ultimate } \\
\text { tensile } \\
\text { strength } \\
(\mathrm{MPa})\end{array}$ & $\begin{array}{l}\text { Ultimate } \\
\text { yield } \\
\text { strength } \\
(\mathrm{MPa})\end{array}$ & $\begin{array}{l}\text { Shear } \\
\text { strength } \\
(\mathrm{MPa})\end{array}$ & $\begin{array}{l}\text { Micro hardness } \\
100 \mathrm{~g} \text { load } \\
\text { (vickers Scale) }\end{array}$ \\
\hline \multirow{4}{*}{$\begin{array}{l}\mathrm{Sn} / \mathrm{Cu}-99.3 / 0.7 \\
\text { (Non SAC) } \\
\text { Lead Free Solder } \\
\text { Melting Point } \\
227^{\circ} \mathrm{C}\end{array}$} & \multirow{2}{*}{$\begin{array}{l}\text { Oxygen+ } \\
\text { Acetylene }\end{array}$} & $\begin{array}{l}\text { Without Nano } \\
\text { Coating }\end{array}$ & 37.89 & 34.67 & 22.76 & 28.97 \\
\hline & & With Nano Coating & 60.23 & 38.98 & 35.06 & 38.65 \\
\hline & \multirow{2}{*}{$\begin{array}{l}\text { Oxygen + } \\
\text { Propane }\end{array}$} & $\begin{array}{l}\text { Without Nano } \\
\text { Coating }\end{array}$ & 44.35 & 42.31 & 26.91 & 34.33 \\
\hline & & With Nano Coating & 70.22 & 45.92 & 41.74 & 43.85 \\
\hline \multirow{4}{*}{$\begin{array}{l}\mathrm{Sn} / \mathrm{Ag} / \mathrm{Cu} \\
96.5 / 3 / 0.5 \\
\text { (SAC) } \\
\text { Lead Free Solder } \\
\text { Melting Point } \\
217^{\circ} \mathrm{C}\end{array}$} & \multirow{2}{*}{$\begin{array}{l}\text { Oxygen+ } \\
\text { Acetylene }\end{array}$} & $\begin{array}{l}\text { Without Nano } \\
\text { Coating }\end{array}$ & 53.10 & 49.41 & 32.04 & 39.93 \\
\hline & & With Nano Coating & 83.76 & 57.25 & 48.32 & 45.32 \\
\hline & \multirow{2}{*}{$\begin{array}{l}\text { Oxygen + } \\
\text { Propane }\end{array}$} & $\begin{array}{l}\text { Without Nano } \\
\text { Coating }\end{array}$ & 58.13 & 54.53 & 34.55 & 45.43 \\
\hline & & With Nano Coating & 87.97 & 60.29 & 51.20 & 51.66 \\
\hline
\end{tabular}

Thus, the results obtained for the soldered work pieces with nano coating were found to be comparatively increasing in all aspects as shown from Figure. 3 to Figure.6.

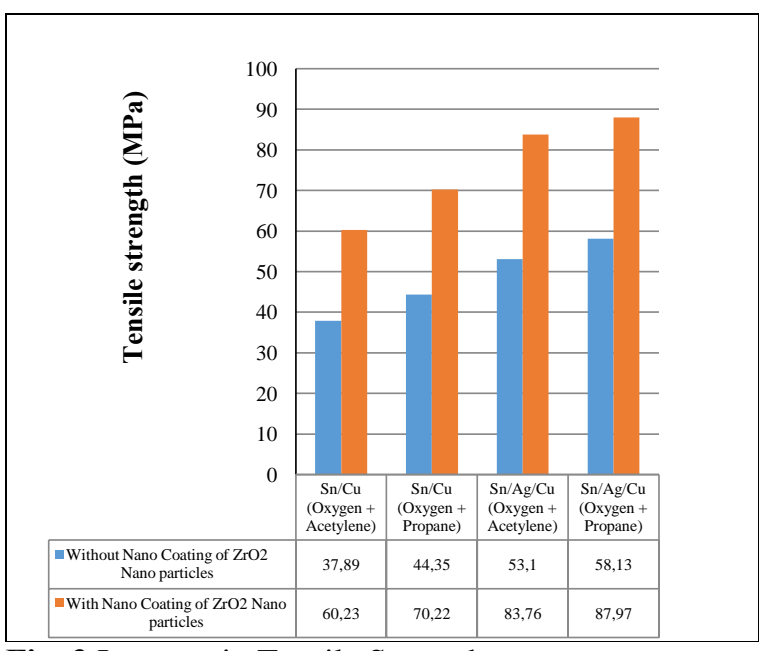

Fig .3 Increase in Tensile Strength

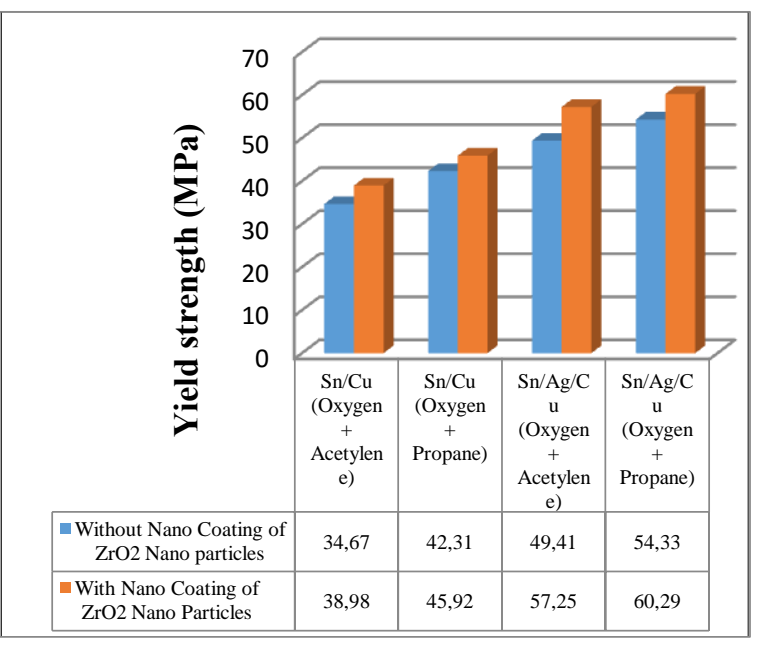

Fig .4 Increase in Yield Strength 


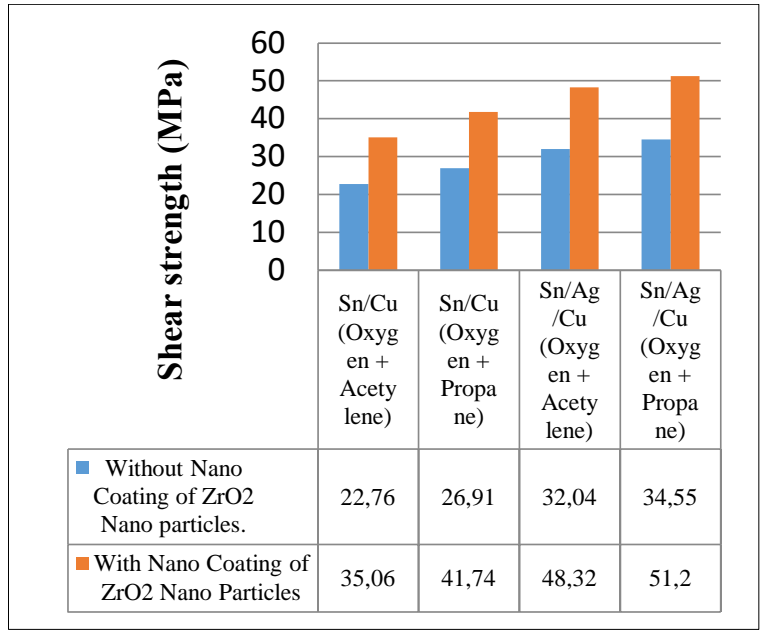

Fig .5 Increase in Shear Strength

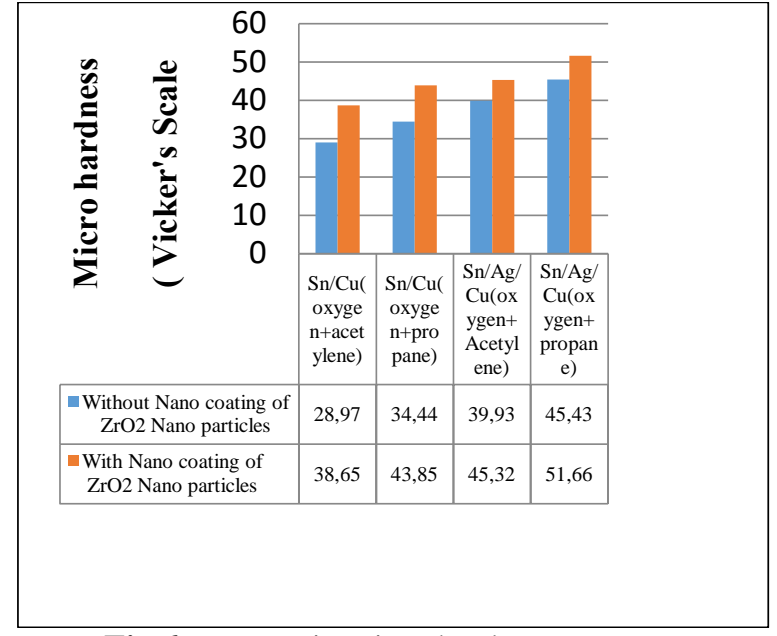

Fig.6 Increase in micro hardness

Thus, a total of 24 tests were taken to find the mechanical properties of the solder with and without the nanostructure coating. And it was observed that the solder properties were considerably increased after the coating. Thus, this nanostructure coating had a great impact over the solder strength and hardness property. Table. 2 consolidates the test results.

Table.2 Test Results

\begin{tabular}{|c|c|c|c|c|c|}
\hline $\begin{array}{c}\text { Type of lead free } \\
\text { Solder }\end{array}$ & $\begin{array}{l}\text { Gases used } \\
\text { for } \\
\text { Soldering }\end{array}$ & $\begin{array}{c}\text { Increase in } \\
\text { ultimate } \\
\text { tensile strength } \\
\%\end{array}$ & $\begin{array}{c}\text { Increase in ultimate yield } \\
\text { strength } \\
\%\end{array}$ & $\begin{array}{c}\text { Increase in shear } \\
\text { strength } \\
\%\end{array}$ & $\begin{array}{c}\text { Increase in micro } \\
\text { hardness } \\
\%\end{array}$ \\
\hline \multirow{2}{*}{$\begin{array}{c}\mathrm{Sn} / \mathrm{Cu}-99.3 / 0.7 \\
(\text { Non SAC) } \\
\text { Lead Free Solder } \\
\text { Melting Point } 227^{\circ} \mathrm{C}\end{array}$} & $\begin{array}{l}\text { Oxygen+ } \\
\text { Acetylene }\end{array}$ & $58.96 \%$ & $12.43 \%$ & $54.04 \%$ & $33.41 \%$ \\
\hline & $\begin{array}{l}\text { Oxygen + } \\
\text { Propane }\end{array}$ & $58.33 \%$ & $8.53 \%$ & $55.10 \%$ & $27.73 \%$ \\
\hline \multirow[b]{2}{*}{$\begin{array}{c}\mathrm{Sn} / \mathrm{Ag} / \mathrm{Cu}- \\
96.5 / 3 / 0.5 \\
\text { (SAC) } \\
\text { Lead Free Solder } \\
\text { Melting Point } \\
217^{\circ} \mathrm{C}\end{array}$} & $\begin{array}{l}\text { Oxygen+ } \\
\text { Acetylene }\end{array}$ & $57.74 \%$ & $15.86 \%$ & $50.80 \%$ & $13.49 \%$ \\
\hline & $\begin{array}{l}\text { Oxygen }+ \\
\text { Propane }\end{array}$ & $51.33 \%$ & $10.56 \%$ & $48.10 \%$ & $13.71 \%$ \\
\hline
\end{tabular}

\section{CONCLUSION}

Thus with the addition of $\mathrm{ZrO}_{2}$ Nano particles over the $\mathrm{Sn} / \mathrm{Cu}$ lead free solders through such as tensile strength yield strength, micro hardness and shear strength increases at an average of $50 \%$. Because of this characteristic feature, the life of the solder joint is increased and it is confirmed that life increase is upto $50 \%$ of the original life. Considering the safe environment impact and high mechanical performance of the lead free solder due to Nano Structured Coatings of $\mathrm{ZrO}_{2}$ Nano particles, $\mathrm{Sn} / \mathrm{Cu}$ lead free solder can be widely preferred for usage in every electronic application like mobiles, laptops, computers etc. Due to the increased life of the soldering, devices with circuit boards can by re-used, re-manufactured and re-cycled even after failing due to stresses and the soldering with Nano 
Electronic waste management for sustainable growth

Coating is commercially successful.Nano Structured Coating of thickness $814 \mathrm{~nm}$, it is evident that the mechanical properties

\section{REFERNCES}

1. Zhang, L. and K. Tu, Structure and properties of lead-free solders bearing micro and nano particles. Materials Science and Engineering: R: Reports, 2014. 82: p. 1-32.

2. Zhao, Z., et al., Effect of nano-Al 2 O 3 reinforcement on the microstructure and reliability of $\mathrm{Sn}-3.0 \mathrm{Ag}-0.5 \mathrm{Cu}$ solder joints. Microelectronics Reliability, 2016. 60: p. 126-134.

3. Chellvarajoo, S., M. Abdullah, and Z. Samsudin, Effects of Fe $2 \mathrm{NiO} 4$ nanoparticles addition into lead free $\mathrm{Sn}-3.0 \mathrm{Ag}-0.5 \mathrm{Cu}$ solder pastes on microstructure and mechanical properties after reflow soldering process. Materials \& Design, 2015. 67: p. 197-208.

4. Chellvarajoo, S., M. Abdullah, and C. Khor, Effects of diamond nanoparticles reinforcement into lead-free $\mathrm{Sn}-3.0 \mathrm{Ag}-0.5 \mathrm{Cu}$ solder pastes on microstructure and mechanical properties after reflow soldering process. Materials \& Design, 2015. 82: p. 206-215.

5. Chellvarajoo, S. and M. Abdullah, Microstructure and mechanical properties of $\mathrm{Pb}$-free $\mathrm{Sn}-3.0 \mathrm{Ag}-0.5 \mathrm{Cu}$ solder pastes added with $\mathrm{NiO}$ nanoparticles after reflow soldering process. Materials \& Design, 2016. 90: p. 499507.

6. Sun, H., Y. Chan, and F. Wu, Effect of CNTs and Ni coated CNTs on the mechanical performance of Sn57. 6Bi0. 4Ag BGA solder joints. Materials Science and Engineering: A, 2016. 656: p. 249-255.

7. $\mathrm{Xu}, \mathrm{L}$. , et al., Design and performance of Ag nanoparticle-modified graphene/SnAgCu lead-free solders. Materials Science and Engineering: A, 2016. 